\title{
Antibiograms of salmonella isolates from poultry farms in Ovia North East local government area, Edo State, Nigeria
}

\author{
Stephen A. Enabulele ${ }^{1^{*}}$, Peace O. Amune ${ }^{1}$, and Wakili T. Aborisade ${ }^{1}$ \\ Department of Biological Sciences, College of Natural and Applied Sciences \\ Igbinedion University, Okada, Nigeria \\ ABSTRACT
}

\begin{abstract}
Water, fecal and swab samples of poultry walls and cages collected from various poultry farms located in five towns and villages in Ovia North east local government area of Edo State, Nigeria, were screened for the presence of Salmonella spp and antibiotic resistance pattern of the isolates. The prevalence rates recorded shows that Salmonella was isolated from all the sources investigated with varying rates which ranged from $27 \%$ for poultry cages to $80 \%$ recorded for fecal samples. Overall prevalence rates based on location ranged from $48 \%$ to $76 \%$. Result of the resistance pattern of the Salmonella isolates from the various farms reveal that $62 \%$ of total 304 isolates tested were resistant to one or more of the antibiotics used with no significant difference in resistance pattern between the locations. Resistance to ampicillin appears to be the most common and was the highest (43\%), followed by trimethoprim-sulphamethozazole (39\%) and streptomycin (29\%), with cephalexin (9\%) and gentamycin (10\%) recording the least resistance. Worrisome however is the fact the fluoroquinolones which are comparatively new, expensive and could be drug of choice should there be an outbreak, showed some significant degree of resistance $(17 \%)$. The findings from this study present a potential health problem and are suggestive of the extent of misuse of drugs in medical and veterinary practice in Nigeria.
\end{abstract}

Keywords: Antibiotics resistance, Poultry, Salmonella spp, Ovia North East L.G.A.

\section{INTRODUCTION}

Salmonella, a primary inhabitant of the gastrointestinal tract, is recognized as one of the most common cause of food borne infection worldwide, resulting in millions of infections and human death annually (Mead et al, 1999). They are carried by a wide range of food and wild animals, rodents, pets, birds, reptiles and insects, usually without the display of any apparent illness (Adams and Moss, 1999). The infections caused by Salmonella are considered one of the most wide spread food -borne zoonotic infection in developed as well as developing countries, though incidences varies between countries (Ostreron, 1999). Food items such as poultry meat and other poultry products (Bryan and Doyle, 1998), have been implicated as important sources of human Salmonella infections outbreak with poultry alone accounting for up to 50 percent of such outbreak (CDC, 1996). Salmonella infections most often manifest themselves as diarrhea, typhoid and paratyphoid fevers. Few people also develop Reiters syndrome, a non specific arthritis coupled with arthritis and conjunctivitis (Ostreron, 1999).

The wide spread use of antibiotics in human veterinary medicine has lead to an increase in the number of resistant Salmonella strain isolated from poultry and poultry environment. (Anthony et al. 2001, Fey et al., 2000). Isolates from poultry, especially those fed with antibiotics as growth hormones could exhibit resistance to antibiotics (Fallow and Keynedy, 2001). In developed countries, stringent control of antibiotic use coupled with effective surveillance of antibiotic resistance patterns in the population, have successfully reduced the prevalence of antibiotic resistance to these agents (Collignon, 2003). The situation in the developing countries like Nigeria is however different, where antimicrobial agents are readily available to people in local drug stores without prescription (Kwaga and Adesiyu, 1984). Such practice has led to misuse of antibiotics with the associated high prevalence of antibiotic resistance among isolates from animal and food sources (Enabulele, et al, 2008).

Consequent upon the above, this study examines and reports the prevalence and resistance pattern of salmonella isolates from poultry farms in Ovia north east local government area of Edo state, Nigeria, especially for the fact that the local government area is a very important source of agricultural produce to Edo and other neighboring states. The study will also serve as guide to treatment and mapping out 
preventive strategies against Salmonella and other zoonotic infections.

\section{MATERIALS AND METHODS}

Sample collection and Isolation: Water and swab samples were collected from various poultry farms located in five towns and villages in Ovia North East local government area of Edo state. Thirty (30) samples each of faeces, poultry wall, poultry cages and water were collected from each of the five locations and cultured for the presence of Salmonella spp. All samples collected were cultured according to the method employed earlier by Enabulele et al. (2008). This was done in selenite $F$ broth in screwcaped bottles and incubated at $37^{\circ} \mathrm{C}$ for $3-5$ days. Subcultures were then made onto plates of deoxychocolate citrate agar, and incubated for another 24hrs. The cultures on nutrient agar plates were then subjected to Gram-staining, motility, urease production, hydrogen sulfide production, and citrate utilization tests. All Gram-negative, rodshaped, motile urease-negative isolates that produced an alkaline slant with acid butt on triple sugar Iron agar slants and are able to utilize citrate as sole source of carbon were regarded as species of the genus Salmonella.

Antibiotic Susceptibility Testing: Antibiotic sensitivity test was conducted using antibiotic disc (Oxoid, UK) according to Kirby-Bauer antibiotic discdiffusion techniques. Briefly described, MuellerHinton agar was prepared in petri-dishes. Pure colonies of the Salmonella isolates were emulsified in normal saline and the turbidity matched against McFarland No. 0.5 turbidity standard. The Isolates were then plated on the Mueller-Hinton agar and antibiotic disc was placed centrally using the antibiotic disc dispenser (Oxoid, UK). The Petri-dish and its content were incubated for 24 hours in a humidified incubator at $37^{\circ} \mathrm{C}$. The organisms were observed for antibiotic sensitivity by measuring the zone of inhibition on the plate.

\section{RESULTS}

Result of the study is as given in tables 1, 2 and 3 below. Prevalence rates of Salmonella spp. from the poultry farms presented in table 1 show an overall relatively high prevalence, with rates ranging from $48 \%$ recorded from farms in Egbeta to $76 \%$.recorded from farms in Usen. The prevalence rates as recorded shows that Salmonella was isolated from all the sources investigated though with varying rates which ranged from $27 \%$ from poultry cages recorded from farms in Egbeta to $80 \%$ recorded from fecal samples from farms in Usen.

Result of the resistance pattern of the Salmonella isolates from various farms reveal that $187(62 \%)$ of the 304 isolates tested were resistant to one or more of the antibiotics used (table 2).Resistance of the isolates ranged from $44 \%$ in Okada to $72 \%$ in Uhen with Egbeta, Ekiadolor and Usen recording 54, 62 and $67 \%$ respectively. There was no significant difference in resistance of salmonella isolates from the different farms $\left(P>0.05, X^{2}\right)$.

The distribution of antibiotic resistance of the salmonella isolates from the poultry farms as presented in table 3 shows that all the farms had isolates that were resistant to one or more of the antibiotics used for the test. Resistance to ampicillin appears to be the highest (43\%), followed by trimethoprim-sulphamethozazole (39\%) and streptomycin (29\%), with cephalexin (9\%) and gentamycin $(10 \%)$ recording the least resistance. The Overall result shows that ampicillin resistance was most common among the various patterns observed.

Table 1: Prevalence rates of Salmonella spp. From Poultry farms in Ovia North East Local Government Area of Edo State

\begin{tabular}{|c|c|c|c|c|c|c|}
\hline \multirow[b]{2}{*}{ Sources } & \multirow{2}{*}{$\begin{array}{l}\text { No of } \\
\text { samples } \\
\text { collected }\end{array}$} & \multicolumn{5}{|c|}{ No.(\%) of Positive Isolates } \\
\hline & & Ekiadolor & Uhen & Okada & Usen & Egbeta \\
\hline Faeces & 30 & 17(57) & $22(73)$ & $18(60)$ & $24(80)$ & $15(50)$ \\
\hline Poultry wall & 30 & 11(37) & $13(43)$ & $9(30)$ & $16(53)$ & $12(40)$ \\
\hline Poultry cages & 30 & $14(47)$ & $18(60)$ & $11(37)$ & $19(63)$ & $8(27)$ \\
\hline Water & 30 & $16(53)$ & 19(63) & $12(40)$ & $17(52)$ & $13(43)$ \\
\hline Total & 120 & $58(48)$ & $72(60)$ & $50(42)$ & $76(63)$ & $48(40)$ \\
\hline
\end{tabular}


Table 2: Resistance of Salmonella spp from various Farms to one or more of the Antibiotics tested

\begin{tabular}{|l|l|l|}
\hline Farm & No tested & No Resistant (\%) \\
\hline Ekiadolor & 58 & $36(62)$ \\
Uhen & 72 & $52(72)$ \\
Okada & 50 & $22(44)$ \\
Usen & 76 & $51(67)$ \\
Egbeta & 48 & $26(54)$ \\
\hline Total & 304 & $187(62)$ \\
\hline
\end{tabular}

Table 3: Distribution of antibiotic resistance of Salmonella isolates from Poultry farms

\begin{tabular}{|c|c|c|c|c|c|c|c|}
\hline \multirow[t]{2}{*}{ Antibiotic } & \multirow[t]{2}{*}{ Concentration } & \multicolumn{6}{|c|}{ No(\%) of Salmonella spp resistant to selected Antibiotics } \\
\hline & & Ekiadolor & Uhen & Okad & a Usen & Egbetá & a All sources \\
\hline Trimethoprim-sulphamethozazol & $30 \mu \mathrm{g}$ & 14(24) & $32(44)$ & $21(42)$ & $39(51)$ & 12(25) & 118(39) \\
\hline Gentamycin & $10 \mu \mathrm{g}$ & $3(5)$ & 8(11) & $6(12)$ & $11(15)$ & $2(4)$ & $30(10)$ \\
\hline Ofloxacin & $10 \mu \mathrm{g}$ & $9(16)$ & $15(21)$ & $11(22)$ & $13(17)$ & $9(19)$ & $57(19)$ \\
\hline Perfloxacin & $10 \mu \mathrm{g}$ & 11(19) & $9(13)$ & 4(8) & $16(21)$ & $11(23)$ & $51(17)$ \\
\hline Ciprofloxacin & $10 \mu \mathrm{g}$ & $18(31)$ & $8(11)$ & $5(10)$ & $9(12)$ & $7(15)$ & $49(16)$ \\
\hline $\begin{array}{l}\text { Amoxicillin-Clavulinic } \\
\text { acid(Augmentin) }\end{array}$ & $30 \mu \mathrm{g}$ & $17(29)$ & $21(29)$ & $6(12)$ & $12(16)$ & $13(27)$ & $69(23)$ \\
\hline & $30 \mu \mathrm{g}$ & $19(33)$ & $27(38)$ & $12(24)$ & $21(28)$ & $10(21)$ & $89(29)$ \\
\hline Streptomycin & $30 \mu \mathrm{g}$ & $13(22)$ & $18(25)$ & 4(8) & $17(22)$ & $8(17)$ & $60(20)$ \\
\hline Nalidixic acid & $30 \mu \mathrm{g}$ & $21(36)$ & $44(61)$ & $10(20)$ & $41(54)$ & $16(33)$ & $32(43)$ \\
\hline $\begin{array}{l}\text { Ampicillin } \\
\text { Cephalexin }\end{array}$ & $10 \mu \mathrm{g}$ & $4(7)$ & $9(13)$ & $3(6)$ & $5(7)$ & $6(13)$ & $27(9)$ \\
\hline Total No of Isolates Tested & & 58 & 72 & 50 & 76 & 48 & 304 \\
\hline
\end{tabular}

\section{DISCUSSION}

Worldwide, poultry farms and meat products from such farms have been implicated as an important source of Salmonella infections (Bryan and Doyle, 1995). The relatively high prevalence rate of Salmonella spp (table 1) isolated in this study should be of concern to health authorities, especially for the fact that the local government area is highly populated as such an outbreak could have dire consequences. The high prevalence could be traced to low sanitary practices observed in most of the farms from all the locations especially those in Usen and Uhen which actually recorded the highest prevalence. This prevalence rate seem to agree with that of Enabulele,et al., (2008) who worked on resistance pattern of salmonella isolates from food, animal and human sources. It also confirm the report of Anyanwu et al., (2010) who observed a pattern of salmonella infection that appear to be spreading among poultry farms in Nigeria in the form of epizootics.

Basically, in livestock production, antibiotics are used for a number of different reasons which include, therapeutic treatment, disease prophylaxis and as growth promoter. The successful use of antibiotics in veterinary medicine not withstanding its use has become particularly worrisome, especially for the fact of the potential to extend such drug into the human food chain or the possibility of reduced efficacy of such drugs which has been observed in some reports to be administered by non- qualified personnel (Boonmar et al., 1998, Thakur and Bajaj, 2006). A recent survey by Alao and Ojo (2007) in Ekiti State, Nigeria, indicate a gradual increase in the use of various antibiotics like the quinolones, gentamycin, neomycin and chloramphenicol which were not normally previously used before now in livestock 
medicine. The relatively high resistance (62\%) of salmonella isolates from the various farms to one or more of the antibiotics tested in this study is quite worrisome and seem to support the observations of Alao and Ojo (2007) and also suggest an indiscriminate use of most of the antibiotic tested.

The finding in this study that resistance to Ampicillin (43\%) and Trimethoprim-sulphamethozazol (39\%) was most prevalent regardless of source, should be attributed to the observation that these drugs are very common and easily available in chemist and patent medicine stores in Nigeria. Most worrisome however is the finding that there is some significant degree of resistance to the fluoroquinolones (Ofloxacin, Perfloxacin and Ciprofloxacin). These antibiotics are comparatively new and expensive as such the resistance to them in this study give a cause for concern as they would have been the antibiotics of choice should there be an outbreak of any enteric infection which include that of salmonella. Cephalexin (9\%) and Gentamycin (10\%) recorded the lowest prevalence rates which suggest they are the least abused of the antibiotics tested in this study. However the $10 \%$ prevalence rate recorded for Gentamycin though low compared to that of Enabulele et al., (2008) is also worrisome for the fact that the mode of dispensing the drug in Nigeria is mostly by injections and are not supposed to be used indiscriminately in livestock medicine.

Conclusively, it is to be noted that antibiotics resistant salmonella constitute a significant and growing problem in poultry and our environment today. The findings from this study therefore present a potential health problem to the populace. It is therefore recommended that good personal and environmental hygiene be encouraged amongst poultry workers to reduce the risk of infection and transmission of this potentially pathogenic bacterium. Also education of the public on the dangers of indiscriminate use of antibiotics and medications especially in poultry and livestock farms is imperative as these drugs can pass on through the food chain to humans.

\section{REFERENCES}

Adams, M. R. and Moss, M. O. (1999). Food Microbiology. $2^{\text {nd }}$ Edition. Royal Society of Chemistry, Cambridge p.390.

Alao, O. S. and Ojo, O. (2007). Use of Antibiotics in food animals ; A case of a major veterinary outlet in Ekiti State, Nigeria. Nigerian Vet. J. 28(1), 80-82.

Anthony, F., Acar, J., Franklin, A., Gupta, R., Nicholis, T., Tamura, Y., Thompson, S., Threllfall, E. J., Vose, D. and van Vuuren M. (2001). Antimicrobial resistance: responsible and prudent use of antimicrobial agents in veterinary medicine. Rev. sci. tech. off. Int. Epiz. 20(3): 829-839.

Anyanwu , A. I., Fasina P.O. Ajayi O.T., Rapu I. and Fasina M. M. (2010). Antimicrobial Resistant Salmonella and Escherichia coli Isolated from Day-old Chicks, Vom, Nigeria. Afr. J. of Clin. and Exper. Microbiol.. 11(1): 129136.

Boonmar, S., Bangtrakulnonth A., Pornruangwong S., Samosornsuk S., Kaneko K. and Ogawa M. (1998). Significant Increase in antibiotic resistance of Salmonella isolates from human beings and chicken meat in Thailand. Vet. Microbiol. 62: 73-80.

Bryan, F. L. and Doyle M. P. (1995). Health risks and consequences of Salmonella and Campylobacter jejuni in poultry. Prot. 8: 326-344

Centers for disease Control and Prevention (1996). Salmonella enteritis Infection and shell eggs - United States. Morbidity and Mortality Weekly Report, 39: 900-912

Collignon, P. (2003). A review - the use of antibiotics in food production animals - does this cause problems in human health. Manipulating pig production IX. Proceedings of the Ninth Biennial Conference of the Australasian Pig Science Association (inc.) (APSA), Femantle, Western Australia, 23-26 November: 73-80.

Enabulele, O. I., Ehwrieme, D. A. and Aluyi H.S.A. (2008). Resistance pattern of Salmonella Isolates from Food, Animal and Human sources to common antimicrobial agents. Glob. J. of Pure and Appl. Sci. 4(2): 179-182.

Fey, P.D., Safranek T. J., Rupp M. E., Dunne E.F., Ribot E., Iwen P.C., Bradford P.A., Angulo F.J., and Hinrichs S.H. (2000). Ceftraxone-Resistance Salmonella Infection Acquired by a Child from Cattle. New Engl. J. of Med. 342(17): 1242

Kwaga, J.K.P. and Adesiyun, A.A. (1984). Antibiograms of Staphylococcus aureus Isolates from Some Ready -toEat Products. J. of Food Protect. 47(11): 865-867.

Mead, P.S., Slutsker L., McCraig, L.F., Bresee, J.S., Shapiro, C., Girffin, P.M., Tauxe, R.V., and Dietz, V. (1999). Food related illness and deaths in the United. Emer. Infect. Dis. 5: 607-625.

Osterom, J. (1999). Epidemiological Studies and Proposed preventive measures in the fight against human Salmonellosis. Int. J. Food Microbiol. 12: 41-52.

Thakur, Y.R., and Bajaj, B.K. (2006). Antibiotic resistance and molecular characterization of poultry isolates of Salmonella by RAPD-PCR. World J. Microbiol. Biotech. 22: 1177-1183. 